\title{
NOS FIOS SIGNIFICATIVOS DA PUBLICIDADE
}

\author{
Ivone Tavares Lucena (UFPB)
}

\section{Introdução}

Sabemos que a propaganda ocupa um grande espaço não só nos meios de comunicação de massa, bem como nas revistas de um modo geral. Diante desta realidade, interessou-nos verificar o funcionamento do seu discurso já que vem se ampliando no nosso diaa-dia. E, por ocupar tão largo espaço e se fazer presente em tudo que nos rodeia, convém analisarmos o poder ideológico que está por trás do discurso publicitário.

Os pressupostos fundamentais de Althusser (1992) sustentam que a ideologia tem existência material e deve ser estudada a partir dessa existência, e que o mecanismo pelo qual a ideologia leva o agente social a reconhecer o seu lugar é o mecanismo da sujeç̧ão. lista sujeição não está presente só nas idéias, mas ela se faz presente num conjunto de práticas virtuais que se inserem em un conjunto de instituições concretas, Aparelhos Ideológicos de Estado. Segundo Althusser, a ideologia existe na prática do sujeito e para sujeitos. Significa dizer que a ideologia existe para sujeitos concretos. Diz ele que a categoria do sujeito preexiste a cada individuo concreto e é uma condição de sua existência social.

Assim, é a ideologia que forma e conforma nossa consciência, atitudes, comportamentos, para moldar-nos às condições de nossa existência social (Santaella, 1996). É por isso que, por meio da ideologia, é fornecida aos indivíduos uma dada formação social, um padrão homogêneo dos modos de interpretar o mundo nas várias formas de sentir, querer, julgar e de se conformar às condições reais de existência.

Considerando que a ideologia pode ser vista como uma "visão de mundo", ou seja, o ponto de vista de uma classe social a respeito da realidade, a maneira como uma classe social ordena, justifica e explica a ordem social, considerando, ainda, que os indivíduos estão inseridos numa determinada classe social com seu conjunto de representações, 
de idéias que revelam a forma de compreensão que essa classe tem do mundo - o que se chama de formação ideológica, compreendemos que é nos discursos que se materializam as representações ideológicas, por isso é que as formações ideológicas só ganham existência nas formações discursivas.

\section{Os discursos publicitários}

Incluindo o discurso da propaganda na dimensão dos discursos socialmente determinados, é possivel fazer uma leitura dos seus mecanismos ideológicos cujos sentidos são manifestações materiais significantes, através das quais descobrimos os significados culturais.

Vivemos numa sociedade de consumo onde a publicidade ganha terreno influenciando o indivíduo a consumir produtos que circulam no mundo socioeconômico-cultural e avançam no universo do consumismo. Nas revistas, por exemplo, a publicidade ganha direções específicas conforme seu leitor virtual. O que significa dizer que a propaganda "manipula símbolos para fazer mediação entre objetos e pessoas, utilizando-se mais da linguagem do mercado que a dos objetos" (Carvalho, 1996:12), e, por isso, possuir objetos passa a ser
sinônimo de alcançar a felicidade; os artefasos e a salvação do homem, representam bem-estos e produtos proporcionam

Com exito (op. cit.: 12).

Com o seu discurso, a propaganda manipula valores, atitudes, conjunto de idéias, representações, impondo pontos de vista de uma classe social dominante. Isto através de coerções sociais, da persuasão, da sedução, do convencimento embutidos numa linguagem específica
que lhe é própria:

[...] a publicidade impōe, nas linhas e entrelinhas, valores, mitos, ideais e outras elaborações simbólicas, utilizando os 1996:13).

Na publicidade, o produto se reveste de poderes mágicos que fazem o consumidor acreditar que sua aquisição e consumo lhe darão juventude, beleza, status, poder, sucesso, felicidade, sexualidade, etc. A linguagem da propaganda "condensa, cristaliza e reflete práticas sociais" (Fiorin, 1990). Conserva, esconde e impõe valores e procura, através da sedução, alterar alguns princípios básicos de conduta do homem. 
A propaganda reflete muito de perto as tendencias do momento e os sistemas de valores da sociedade (Vestergaad, 1994:160). Alguns anúncios publicitários são muito sutis e mais perigosos, do ponto de vista ideológico, porque a norma por eles estabelecida permanece no nível latente "natural", o que significa que o leitor aceita a norma como inquestionável, sem submetê-la ao exame consciente da razão.

A forma de persuadir varia conforme o produto e conforme a idade, o sexo e a classe social do provável comprador e age de uma forma estratégica para seduzir um determinado público. Esconde, pois, uma formação ideológica que se materializa nas formaçõcs discursivas.

As propagandas que aparecen em revistas femininas rivestem-se semântica e ideologicamente de forma diferente das que fazem as revistas masculinas.

Ao analisarmos as propagandas de revistas femininas $e$ compararmos com as de revistas masculinas, veremos um "enunciador", enquanto suporte da ideologia, que direciona seu discurso de acordo com a reprodução do dizer de um grupo social, de una formação social. Há um sujeito que "fala" de um lugar social, um sujeito que responde por um discurso especifico institucionalizado conforme uma determinada formação discursiva.

Nas revistas masculinas, por exemplo, há um sujeito que reproduz valores e condutas de uma sociedade que vê o homem como objeto do desejo e da conquista feminina. Aquele que é responsável pelo sustento da família, aquele que se mantém com o poder de compra, poder de conquista e de escolha. Aquele indivíduo socialmente viril, sexy e livre para se deliciar com exposição de mulheres nuas, lindas e que provocam e aumentam a sexualidade masculina. Seu papel continua sendo o papel de macho, dono do prazer, da escolha, do poder, do espaço, corroborando assim uma estrutura social machista, detentora de una ideologia que determina um lugar de poder, posse, virilidade e sabedoria masculinas.

Dessa forma, as revistas masculinas direcionam suas propagandas para uma conservação da virilidade do homem como objeto do desejo e da conquista feminina. Propagandas como cartões de crédito, carros (importados ou não), relógios de marca, 
computadores, equipamentos eletrônicos, bancos, perfumes, bebidas sofisticadas e importadas, motéis, põem o homem no seu lugar social: superioridade, poder aquisitivo, sexualidade e virilidade fazem dele o objeto de procura das mulheres, conservando, assim, valores de uma sociedade machista, patriarcal, em que o homem mantém o poder.

E esse poder é figurativizado pelo carro que possui, pelos cartões de crédito que tem, pelos motéis que freqüenta, pelos perfumes caros e importados que usa, pelas roupas que veste, pelo cigarro que usa, pela bebida que toma. Tudo o coloca em situação de poder, de sucesso e de superioridade, tornando o objeto de busca da mulher que precisa estar "adornada" para alcançá-lo, ser feliz e poder sobreviver à sombra do homem.

As mulheres nuas, que aparecem na revista Playboy, fazem parte da publicidade que eleva a sexualidade e faz do homem mais viril, tendo sempre as mulheres correndo atrás dele. $O$ poder econômico - do banco, dos cartões de crédito, das roupas e sapatos caros - o põe em situação de privilégio diante da sociedade, e ele se defende daquelas mulheres "caça-dotes". Isto porque ainda existem valores cristalizados pela sociedade, de que o homem é o cabeça da família, é o responsável pelo sustento da casa, das despesas, e que à mulher compete o estigma de "rainha do lar", de "dona-de-casa". Sempre na dependência masculina quanto à sua sobrevivência.

As propagandas das revistas masculinas são sempre um convite ao prazer sexual do homem, são sempre um enlevo à sua potencialidade, à sua virilidade e à sua situação econômica diante da sociedade, conservando valores arraigados e cristalizados por uma classe social dominante que ainda coloca o homem como seu dirigente, inteligente e capaz de mantê-la de pé enquanto sociedade.

Enquanto as revistas masculinas conservam os valores potenciais masculinos, as revistas femininas tratam as mulheres como "incapazes", "incompetentes" e que precisam estar sempre belas para conquistar aquele que as sustentará e as manterá diante da sociedade. Por isso as sessões "como prender o seu homem", "você é capaz de conquistar o seu homem?". A publicidade das revistas femininas está sempre voltada para o consumismo de produtos que farão delas mulheres lindas e "prontas" a ir à caça do seu homem. E, para alcançar sucesso nessa "caça", elas precisam de produtos como roupas, sapatos e adornos, que lhe dêem competência para isto. Elas não podem 
envelhecer - devem consumir produtos anti-rugas, não podem engordar - devem usar produtos diets e remédios emagrecedores, cintas, freqüentar academias para manter o corpo sempre esguio e em forma, devem estar sempre de cabelos lindos e sem fios brancos - por isso precisam usar determinados xampus e tinturas que lhe escondem o tempo e o próprio cabelo. Devem estar com os olhos, a boca e as unhas bem delineadas para poder ser vistas e cobiçadas - daí a publicidade de rímel, batons, lápis de sobrancelhas, esmaltes etc., produtos estes que são capazes de manter a beleza, a forma. Tudo são valores que a sociedade patriarcal impõe à mulher que deseja, precisa e pretende conquistar o seu "sustentador", o seu "mantenedor".

As rendas, as cores das roupas íntimas que manterão as formas e a beleza da mulher, são as responsáveis pela "sedução" sexual, pela "potência", porque o homem se interessa apenas pela "forma" em que se encontra o seu objeto do desejo. Por isso a ironia, a crítica e a exposição do ridículo das mulheres ditas "feias", consideradas "velhas" e vistas como "gordas".

As propagandas, que se fazem presentes nas revistas ditas femininas, têm como público-alvo a figura feminina. cuja imagem, numa sociedade patriarcal, vem sendo construída, ideológica e culturalmente, como frágil, como aquela que deve ter e tem de ser uma figura bela, jovem e "caçadora" do homem que será o seu parceiro-protetor pelo resto da vida. À mulher é dada a tarefa de responsabilidades do lar (rainha do lar, doméstica), aquela que não pensa, não contribui para a construção de uma sociedade cheia de progresso e conquista. Isto cabendo ao homem. E, por isso, coloca-se a mulher em posição de inferioridade, fracașso, submissão, torna-se uma "máquina" que precisa estar sempre "assistida" para não falhar em suas "funções". Dessa forma, o discurso "da propaganda, direcionada à mulher, reveste-se semanticamente de figuras que revelam uma formação ideológica/formação discursiva que coloca a mulher num lugar social de desprivilégio.

Entretanto, a figura masculina vai sendo construída ideológica e culturalmente como detentora da sabedoria, do sucesso, da inteligência, do poder (aquisitivo) e de sucesso que o conduz à superioridade. Ao homem é dada a responsabilidade do progresso da ciência, da pesquisa, da economia, da construção da sociedade. É através de formações sociais que se constrói a figura masculina e o 
papel que deve desempenhar na sociedade. O que cristaliza una imagem de superioridade, sucesso, poder e êxito. Por isso a publicidade que se destina ao homem nas revistas - especialmente masculinas - cristalizam essa imagem e conservam tais valores ideológicos.

A título de exemplo, escolhemos algumas propagandas destinadas ao público feminino e outras direcionadas ao público masculino para podermos corroborar a idéia de que há um "enunciador" que sustenta um discurso que responde por valores ideológicos, estes materializados por formações discursivas. Diz Fiorin (1990:42) que o dizer desse enunciador é a produção inconsciente do dizer do seu grupo social.

\section{Nos fios significativos da publicidade}

A propaganda $\mathrm{n}^{\mathrm{0}} 1$ (Clíudia, 0441, n. 419, ago. 1996) coloca a mulher na posição de objeto, de máquina. E uma "máquina" precisa de manutenção para poder funcionar. Caso a mulher não mantenha sua forma em dia, sua aparência, sua beleza bem tratada, não conseguirá alcançar o seu "príncipe encantado" porque a beleza é fundamental aos olhos masculinos. Aqui nesta propaganda, cedo ou tarde toda máquina precisa de assistência técnica, escondem-se valores ideológicos de uma formação social que coloca a mulher em um lugar social: aquela que é vista socialmente como objeto de consumo, aquela que precisa conservar-se bela, perfeita, jovem, de corpo esguio, seios rijos para poder correr atrás do "prestígio", do seu "protetor" que a fará "brilhar" na sociedade à sua sombra. Ao ser colocada como máquina, a mulher não tem cérebro, sendo portanto destituída de inteligência e conseqüentemente de êxito, futuro e progresso. Seu sucesso não é o pensar, agir, mas o SER BELA, ATRAENTE e de silhueta perfeita para agradar os olhos masculinos. O que estigmatiza mais ainda a sua "fragilidade", "fraqueza" e "incompetência". 


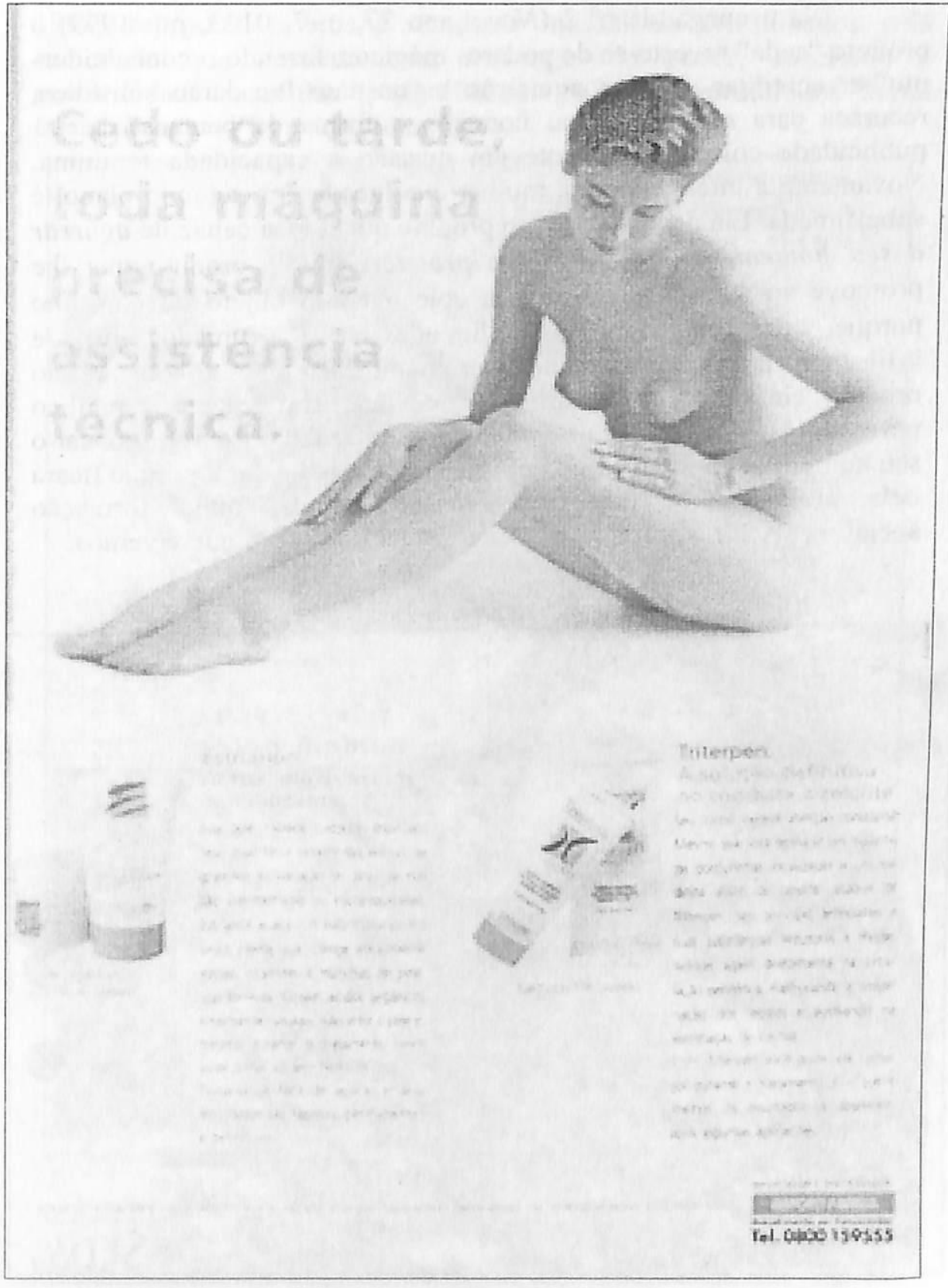

Figura 1 
Na propaganda $\mathrm{n}^{\mathrm{o}} 2$ (Nova, ano 27, n. 7, 0133, jul. 1999) o produto "seda" reveste-se de poderes mágicos, fazendo o consumidormulher acreditar que sua aquisição e consumo lhe darão subsídios, recursos para agarrar o seu homem. A forma de persuasão desta publicidade coloca novamente em questão a capacidade feminina. Novamente a inteligência da mulher é colocada em segundo plano, é subestimada. Ela necessita de um produto que a faça capaz de agarrar o seu homem, de agarrar o seu protetor. E é o produto que lhe promove ao status da beleza e a coloca como objeto de consumo porque, com cabelos belos, perfumados, bem arrumados, lisos e brilhantes ela será vista e poderá ser conquistada. Com o consumo do produto ela obterá uma forma estratégica para seduzir o público masculino e agarrar o seu homem, garantindo-lhe o futuro. O fisgar o seu homem deve-se ao "sucesso" que o produto lhe dará, porque ficará bela, atraente e perfeita, valores estes latentes numa formação social/formação discursiva da sociedade patriarcal em que vivemos.

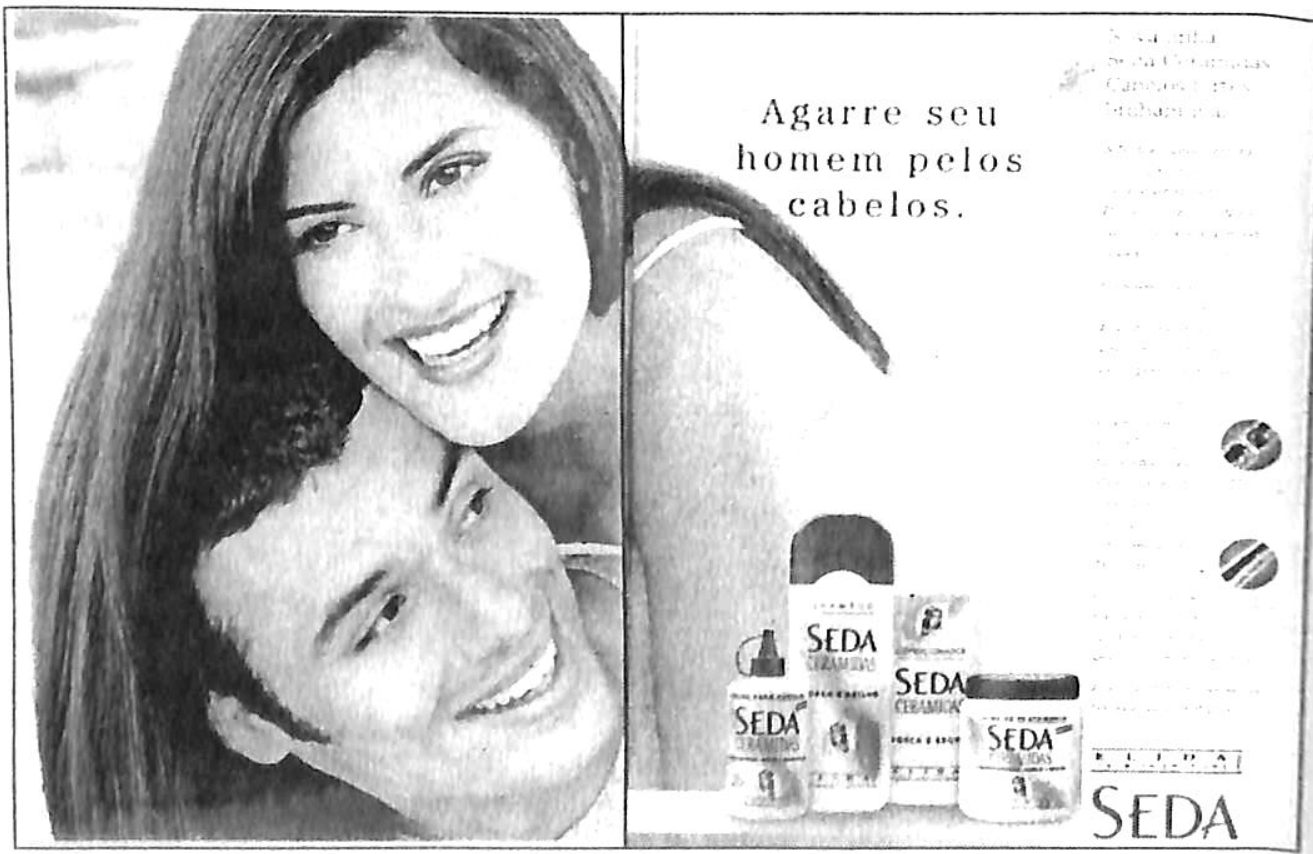

Figura 2 
A propaganda $\mathrm{n}^{0} 3$ (ver Playboy, ano XXIV, n. 280, nov. de 1998) reproduz valores e condutas masculinas cristalizados pela sociedade que sustenta uma ideologia do poder, soberania e autenticidade masculinas, significados culturais estruturados numa formação social/formação ideológica.

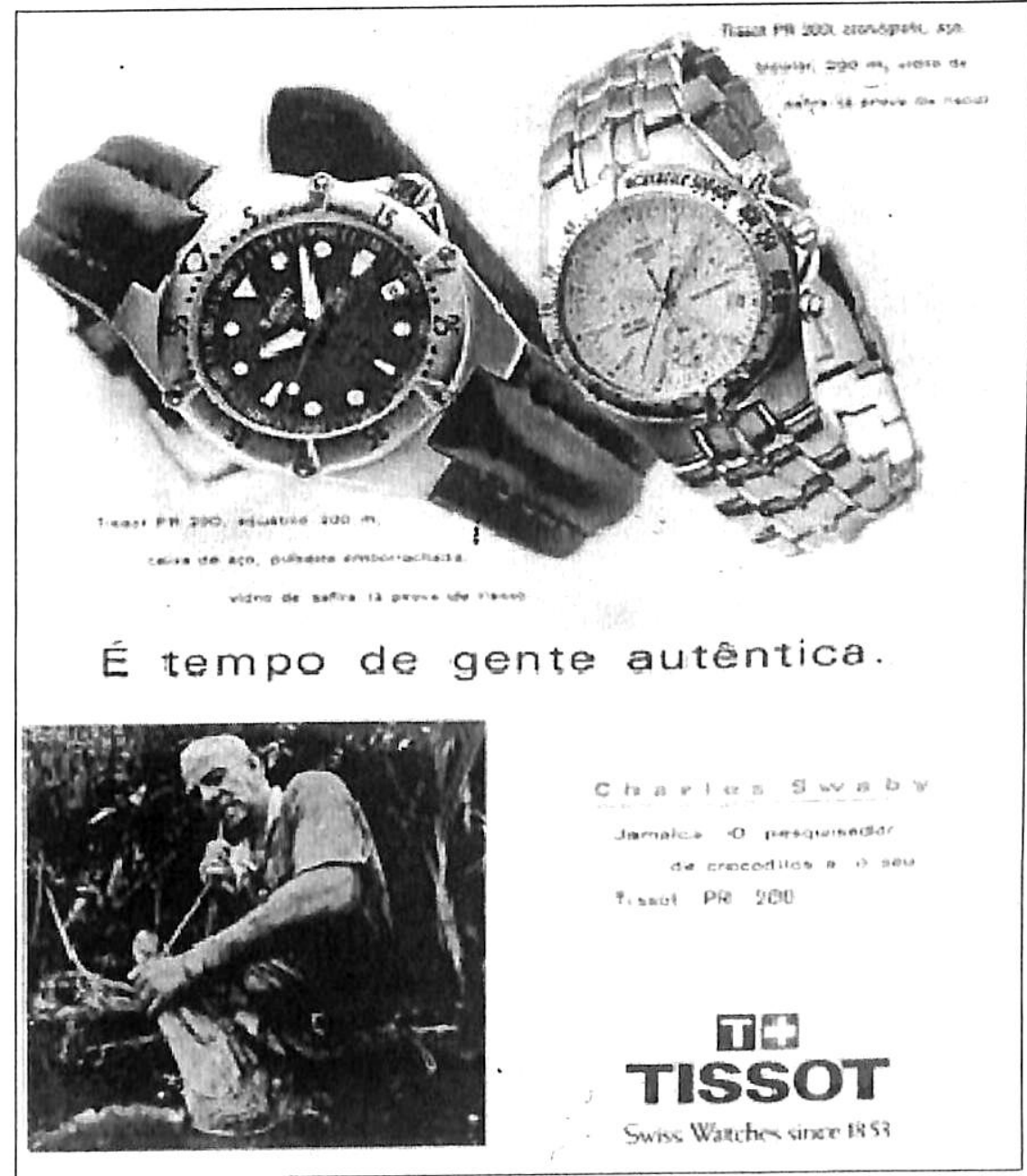

Figura 3

O discurso que sustenta este texto publicitário vem de um lugar social que "fala" em nome da instituição sociedade machista, em que os valores do homem são sempre voltados para o futuro, a autenticidade, a inteligência, o progresso, o sucesso. Aqui, o homem 
não é colocado como aquele que precisa de adornos (como a mulher) para ser atraente aos olhos femininos; porém, ao usar o relógio TISSOT, ele corrobora sua autenticidade, inteligência. Só as pessoas inteligentes, pesquisadoras e autênticas usam o relógio TISSOT, o que é próprio do homem.

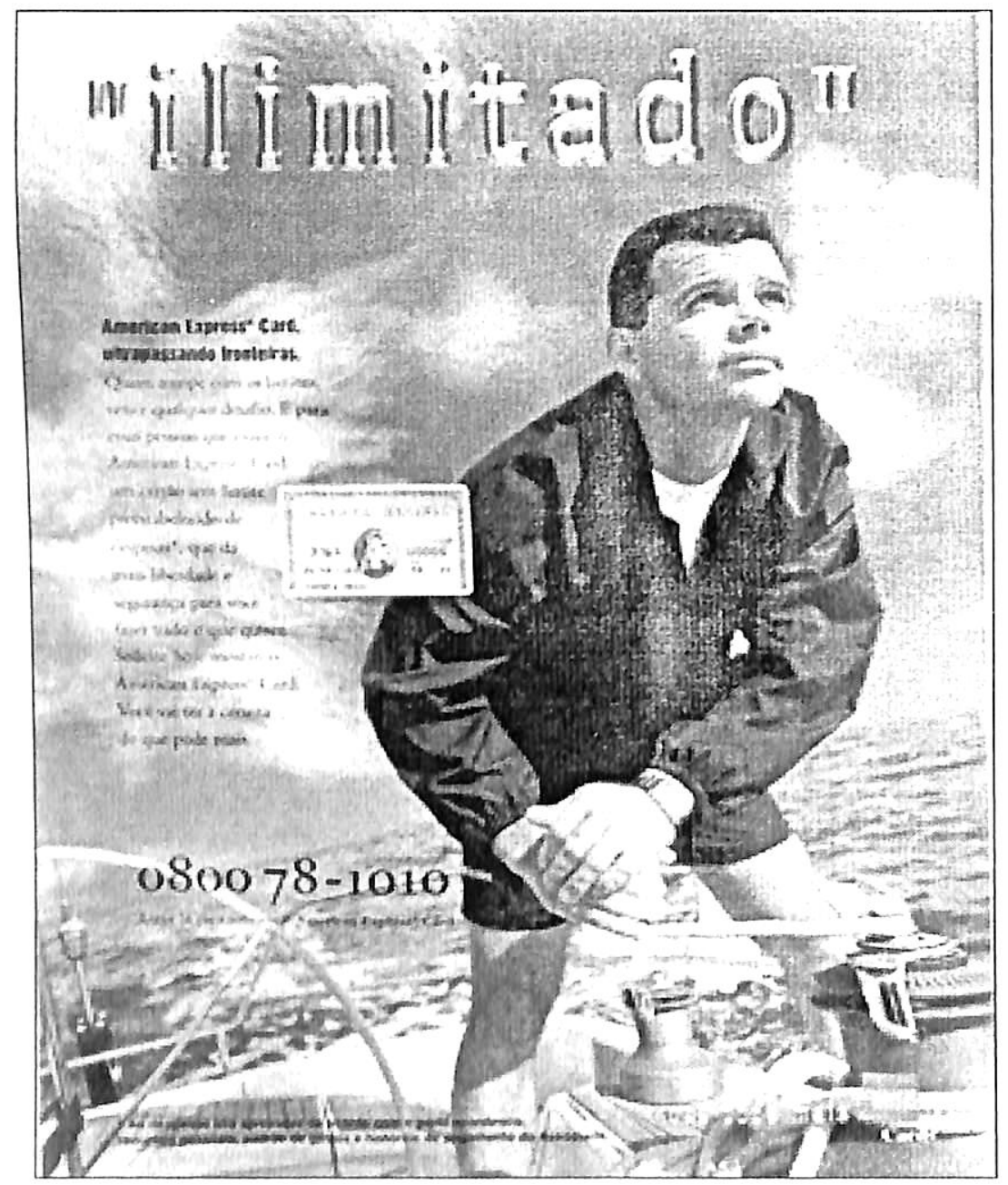

Figura 4

Na propaganda no 4 (Playboy, ano XXIV, n. 284, mar. 1999), o possuir o cartão de crédito AMERICAN EXPRESS faz sustentar o estigma de ilimitado, porque o homem, na sociedade machista, é ilimitado, ele pode tudo. 
A ele é permitido tudo, só ele pode ter o cartão AMERICAN EXPRESS porque só ele "rompe limites", "vence qualquer desafio" e tem "segurança", assim como o CARTÃO. O poder aquisitivo do homem lhe confere o perfil econômico, os recursos pessoais, o padrão de vida que é próprio do sucesso masculino. Não é o cartão que vai adorná-lo para ficar lindo a fim de ser objeto de conquista da mulher, mas é seu perfil de homem que lhe dá o direito social de possuí-lo, reforçando o poder e o status que a sociedade lhe confere, valores ideológicos arraigados que se perpetuam de geração a geração.

A propaganda no 5 (Playboy, ano XXIV, n. 284, mar. 1999) esconde um discurso machista e põe o homem no lugar social em que a sociedade patriarcal o concebé. O design da caneta PARKER reveste semanticamente o porte, o design masculino. É o homem que assina "tratados, pactos e acordos mais importantes do mundo". Assim como a caneta, o homem "marca a história" porque é "pessoa especial", porque é pessea "exclusiva" e "nobre". Novamente temos um discurso que "fala" da posição social do homem, seu poder de inteligência, de conquista, de sucesso. O texto que vem como adendo, entre parênteses (mas o que vai conquistar mesmo vocêé o seu design), coloca o homem no lugar de ser conquistado, de ser procurado porque ele é nobre, inteligente, marca história e é pessoa especial, o que faz do seu design uma figurativização desse poder, dessa nobreza, dessa inteligência. Ele não é "adornado" pela caneta mas é comparado ao desempenho, beleza e importância que tem a caneta.

\section{Conclusão}

Considerando que os indivíduos estão inseridos numa determinada classe social com seu conjunto de representações, de idéias que revelam a forma de compreensão que essa classe tem do mundo - o que se chama formação ideológica, entendemos que os discursos circulam nos lugares sociais e que apresentam a produção de uma identidade ideológica. E é por meio do discurso que se descobre quem é que "fala" e qual a sua visão de mundo. É por meio do componente semântico, contido no discurso, que se determina a visão de mundo que é veiculada pela linguagem. É o que acontece com o discurso publicitário, torna-se um instrumento de controle, de sedução e persuasão. A todo momento o discurso da propaganda procura instigar o receptor com suas coerções sociais, convencendo-o de 
forma consciente e/ou inconsciente. Dessa forma, o discurso da propaganda manipula valores ideológicos, atitudes impondo conjunto de idéias de uma classe social dominante.

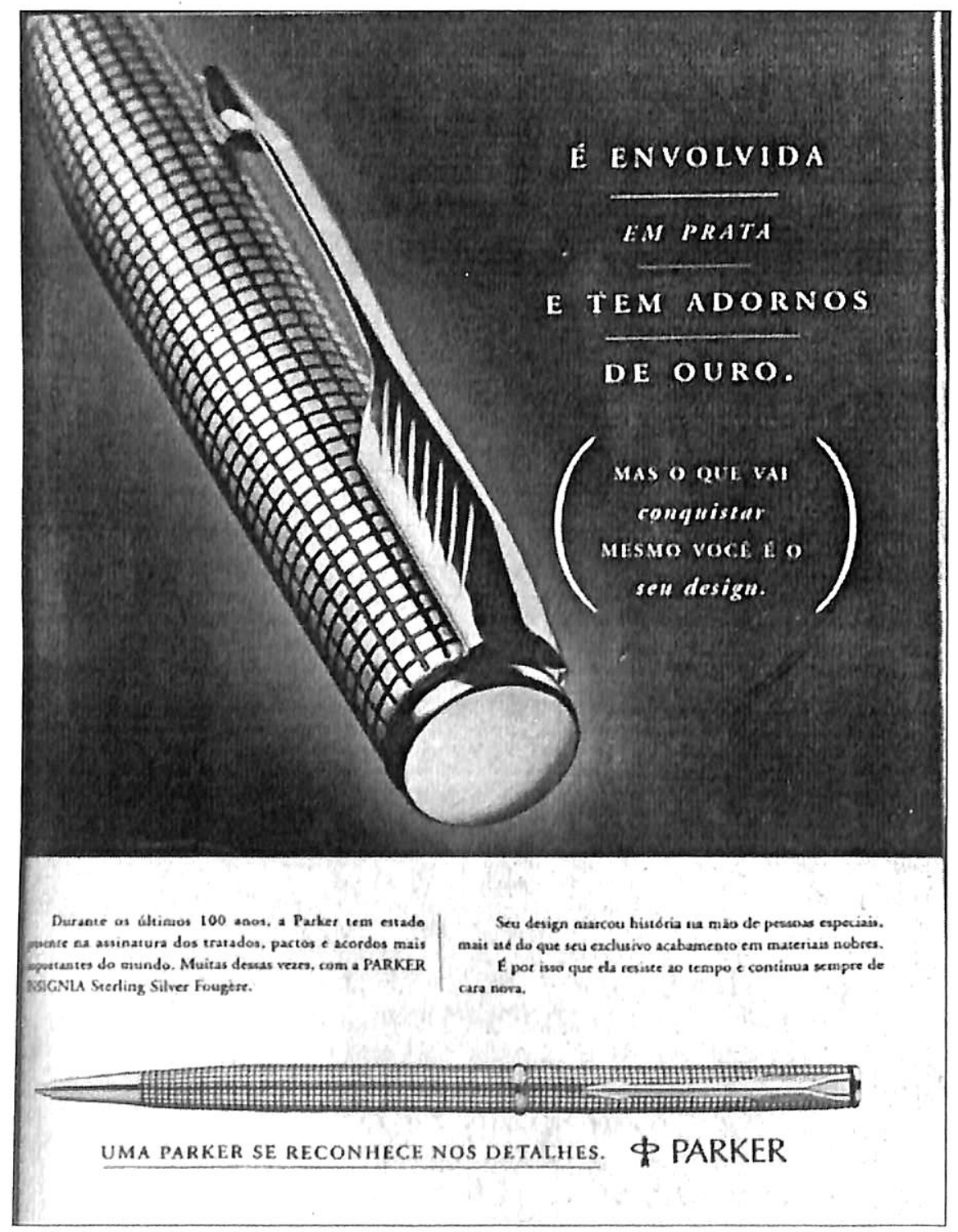

Figura 5 
As propagandas destinadas ao público feminino manipulam valores ideológicos de submissão, fragilidade, incompetência, dependência e desprestígio, enquanto as destinadas ao público masculino conservam valores ideológicos de virilidade, poder, sucesso, liberdade e sexo forte.

O discurso da propaganda é, pois, uma construção ideológica que influencia o indivíduo a consumir produtos, convencendo-o, seduzindo-o, persuadindo-o e impondo valores sociais e ideologicamente cristalizados por formações ideológicas/formações discursivas, legitimando uma sociedade patriarcal e cheia de valores e práticas discursivas.

\section{REFERÊNCIAS BIBLIOGRÁFICAS}

BRANDÃO, R. H. N. Introdução à análise do discurso. Campinas: Editora da UNICAMP, 1995.

BROWN, J. A. C. Técnicas de persuasão: da propaganda à lavagem cerebral. Rio de Janeiro: Zahar, 1971.

CARVALHO, N. de. Publicidade: a linguagem da sedução. São Paulo: Ática, 1996.

FIGUEIREDO, I. de L. Fiando as tramas do texto: a produção de sentidos no Atelier de Leitura e Produção Textual. Araraquara: Tese de Doutoramento, UNESP/SP, 1998.

FIORIN, L. Linguagem e ideologia. São Paulo: Ática, 1990.

GREGOLIN, M. R. F. V. As fadas tinham idéias: estratégias discursivas e produção de sentidos. Araraquara: FCL, Tese de Doutoramento, 1988.

Revista Cláudia, São Paulo, Ed. Abril, ano 35,n. 8:141, ago. 1996.

Revista Nova, São Paulo, Ed. Abril, ano 27, n. 7:24-25, jul. 1999.

Revista Playboy, São Paulo, Ed. Abril, n. 284:contra-capa, mar. 1999.

Revista Playboy, São Paulo: Ed. Abril, n. 280:163, nov. 1998. 
SANDMANN, A. J. A linguagem da propaganda. 2. ed. São Paulo: Contexto, 1997.

SANTAElla, L. Produção de linguagem e ideologia. São Paulo: Cortez, 1996.

VERÓN, E. A produção do sentido. Trad. Alceu Dias et al. São Paulo: Cultrix/EDUSP, 1980.

WESTERGAAD, T. e SCHØDER, K. A linguagem da propaganda. Trad. João Alves dos Santos. 2 ed. São Paulo: Martins Fontes, 1994. 